\title{
What a difference depth makes
}

\author{
A profundidade faz toda a diferença
}

DiNA MENDONÇA ${ }^{a}$

\begin{abstract}
The article explores how a new dimension of emotion - depth - is crucially important for a better understanding of emotion and its connection to rationality. It begins by identifying that depth is trapped in a circularity in which deep emotions are important because they refer to deep and important aspects of people's lives. Following Danto's discussion of deep interpretation (1981), it suggests that it is the contrast between deep and superficial that grants emotional perspective and the ability to identify levels of emotional depth. After arguing that the emotional perspective is grasped by the narrative structure of emotion, it raises several objections that provide the ground to establish a difference between deep and profound. Then the paper concludes that the meaning of emotional depth is only fully understood in the ongoing contrast with the superficial described before, and states how further research on depth of emotion may provide the key to understanding the ambivalent status of emotions regarding their link to rationality.
\end{abstract}

Keywords: Emotional depth. Narrative structure. Profound. Emotional perspective. Rationality.

\section{Resumo}

O artigo explora como a profundidade - uma nova dimensão da emoção - é decisiva para uma melhor compreensão da emoção nomeadamente na sua conexão com a racionalidade. $O$ artigo começa por identificar como o conceito de profundidade está circularmente preso porque se considera que emoções profundas são importantes porque se referem a aspectos profundos e importantes da vida das pessoas. Após a descrição da discussão de Danto sobre a interpretação profunda (1981) conclui-se que é o contraste entre profundo e o superficial que oferece a possibilidade de colocar as emoções em perspectiva e a identificar vários níveis de profundidade emocional. De seguida argumenta-se que a perspectiva emocional é apreendida através da estrutura

\footnotetext{
a IFILNOVA, Faculdade de Ciências Sociais e Humanas NOVA FCSH, Universidade Nova de Lisboa, Lisboa, Portugal. Doutor em Filosofia, e-mail: md@fcsh.unl.pt
} 
narrativa da emoção. Depois de levantar várias objeções que fornecem o terreno para estabelecer uma diferença entre as emoções profundas e as emoções de fundo, conclui-se que o significado de profundidade emocional só é totalmente compreendido no contraste com o superficial sublinhado anteriormente. $O$ artigo termina afirmando que a análise feita mostra a possibilidade de novas investigações sobre o modo como o nível de profundidade de uma emoção pode fornecer a chave para melhor entendermos o estatuto ambivalente das emoções na sua relação com a racionalidade.

Palavras-chave: Profundidade emocional. Estrutura narrativa. Profundidade. Perspectiva emocional. Racionalidade.

Emotional depth is an aspect of Emotion Theory that is still to be fully explored. Though depth is undeniably important for phenomenal experience and emotion (Gaebler et. al. 2013) it remains an issue to be thoroughly researched. Partly because often the criteria for identifying and understanding emotional depth is simplistically trapped in circularity by claiming that deep emotions are important because they refer to deep and important aspects of people's lives. This paper offers a novel way to capture emotional depth claiming that the narrative structure of emotions holds the key to understanding why some emotions are at the surface while others are hidden, and also the way to fully comprehend why some emotions are more decisive, deeper and profound than others.

\section{Emotional Depth}

Mind has depth. Though this fact is undeniable, and depth is crucial for understanding experience (Gaebler et. al. 2013), reflection upon its place in understanding emotions, mind and experience is sparse. Accordingly, Danto points out in "Deep Interpretation" (1981) that

surface interpretation, which we are all obliged in the course of socialization to become masters of, has been extensively discussed by philosophers in the theory of action and in the analysis of other languages and other minds. But deep interpretation has been scarcely discussed at all. (Danto 1981, 695).

Similarly with emotions: though depth is an important part of understanding them and their connection to other aspects of the mind, reflection and discussion about emotional depth is rarely the focus of philosophical work. Echoes of this assessment can be found in Cataldi's book Emotion, Depth, and Flesh: A study of Sensitive Space (1993), when she writes, "[d]espite our implicit understanding of the 
phenomenon of emotional depth, there is next to no philosophical literature devoted to the topic" (Cataldi 1993, 1). She names two exceptions: Max Scheler's discussion of the stratification of emotional life in Formalism in Ethics and Non-Formal Ethics of Values (1973), and John Dewey's early work on the deepening of emotional feeling discussed in his Psychology (1887). More than twenty years later we can add two references to this list: Cataldi's book and Pugmire's Sound Sentiments (2005). In sum, even though understanding emotional depth is crucial to the field of emotions and is in part recognized in the literature because of its impact on mental health and education (e.g. Ben-Ze'ev 2000, 485; Baier, 1990, 4), it is still open for research how emotional depth is to be understood, fostered, and enhanced for a complete picture of emotions and of the mind.

At first sight the difference between deep and shallow emotions is given by how certain emotions are connected to crucial and deep structures of life and the self. Pugmire writes that, “depth depends at least on how much of a person's life is affected by what evokes the emotion (e.g. Fear of what threatens everything I have striven for)" (Pugmire 2005, 43). That is, the difference is grasped by acknowledging that if these deep emotions were not in place it would change drastically the meaning of life, and the identity of the self. In contrast, shallow emotions are connected to things that are less important, and which would not be missed if they ceased to exist or if they were altogether absent. This means that fear will be deep if something threatens one's life, or if there is a threat to a crucial relationship or value held by the self; and the fear will be shallow if it arises with less important issues such as feeling scared of being overly dressed for a certain occasion. That is, even though we use the same word to describe the emotional experience, it is unquestionable that in one instance the fear is deep and in the other it is shallow.

Cataldi claims that we do not experience "deep emotions over things that are manifestly superficial" (Cataldi 1993, 2), and consequently emotional depth is already given and differentiated in our life. Cataldi also thinks that the difference between deep and shallow emotions is mirrored in our vocabulary such that "cruelty is deeper than spite, awe is deeper than admiration, sorrow is deeper than sadness, joy is deeper than gladness, reverence is deeper than respect; and so forth" (Caladri $1993,7)$. She would perhaps argue that the use of fear in the example above of being 
overly dressed for an occasion is a misuse of language, and that one could more adequately describe the emotional experience as a slight sense of anxiety about fitting in. According to Cataldi, all that is required for dealing with emotional depth, and to differentiate it from shallow emotional experience, is to trust the use of language because people know that they should use remorse instead of regret when the issue is deeper.

The fact that emotional depth can be given in language means that somehow it must also be already present in the phenomenology of emotions, and one can count on people's ability to distinguish the deep emotions from the shallow ones and to name them adequately. And, this is why people recognize when something emotionally deep has happened to them by its impact, longer duration and greater intensity.

However, sometimes people are not capable of properly naming their feelings (e.g. Pugmire 1994, 108; Haybron 2007, 394). And even thought there are some particular emotions that are not possible to experience superficially for "we cannot be rather grief-stricken, hate half-heartedly, or be a touch ecstatic" (Pugmire 2005, 31), some emotions can both be experienced superficially on some occasions and more deeply on others, as when a person "can be furious or just annoyed, and either slightly or desperately worried." (Pugmire 2005, 31) Accordingly, Pugmire states that emotional depth requires a more rigorous description than the criteria given by language refereed by Cataldi. This explains why a full grasp of emotional depth requires education, training and sometimes even professional help from experts of the mental health sector.

Pugmire proposes three conditions that make an emotion deep: (1) it must be cognitive (believed instead of entertained), (2) it must hold a certain range of response regarding the wholeness of mind, and (3) there must be a harmony "between the significance I give to something (in (1) and (2)) and its actual magnitude" (Pugmire 2005, 49). The advantage of Pugmire's criteria is that it moves the discussion beyond the scope of psychological and phenomenological descriptions of the experience of emotion offered by Cataldi, and opens an understanding of emotional depth capable of a description that "depends on more than personal susceptibility and is not just a property of emotional experience on 
its own" (Pugmire 2005, 33). Thus, while Cataldi's understanding of depth only requires trust in the subjective phenomenology of the emotional landscape and a good grasp of emotional vocabulary, for Pugmire depth depends on the world such that "the character of that world may decide the quality of responses available to an individual" (Pugmire 2005, 33). Consequently, the conditions that enable depth of emotion are "indeed partly external to the emotion; and not only partly but heavily so" (Pugmire 2005, 33), requiring an evaluation of the phenomenology of experience and of the situation in which it arises. By including the external conditions of emotional experience, Pugmire does justice to the Janus-faced nature of emotions, and adds to the picture of emotional depth this long recognized feature of emotions that " $t]$ hey tell us something about the world, and they tell us something about ourselves" (De Sousa 2007, 323). So emotional depth is similarly measured by combining its internal and external aspects, and therefore "emotions could acquire depth from the person's concerns (e.g. desires, needs, valuations, other emotions) in the same way they draw on depth of belief' (Pugmire 2005, 40).

Given the need to incorporate the elements of the subject and the elements of the world, as well as a sense of harmony between them, Pugmire concludes that an emotion cannot be deep unless it is morally adequate (Pugmire 2005, 63), turning the insightful recognition of emotion's Janus-faced nature into the conclusion that depth of emotion reflects the deep elements of life. He writes,

Depth of emotion, then, may reflect excellence of character. Through such emotion a person participates as fully as possible both in his own life and in that of the world through which he passes. By the same token, deep emotion is a reflection of the world. If the elements of someone's life or of the world are themselves shallow, so are their proper emotional resonances (Pugmire 2005, 64).

The end result of Pugmire's definition points to a similar implication Cataldi's: namely, that it is not possible to feel deeply about superficial things, nor feel superficially about deep things because "profundity of emotion depends on the quality of its subject matter" (Pugmire 2005, 58). That is, even though Pugmire's requirements for emotional depth are more rigorously demanding it is still the case that depth appears trapped in a circularity in which deep emotions are important because they refer to deep and important aspects of people's lives. And except for those who hold excellence of character, most people will oscillate between sometimes making the proper and adequate judgment with the right intensity and 
with perfect harmony between significance and magnitude, and other times they will not succeed in attaining such clarity of understanding on the level of depth of their emotions. Thus the issue returns to the same difficulty: people are not always clear about what counts as depth in their emotional experience, even though there are some common sense guiding assumptions about when emotional depth is present.

Take, for example, how the temporality of emotions gives us some insight into their depth. When emotions are brief or short, they can more easily be labeled as shallow, in contrast with enduring ones. Nevertheless, it remains the case that duration is not a sufficient condition to label an emotion as deep. Sometimes one may feel a deep emotion even though it does not persist for a very long time. And sometimes a superficial emotion can last because, as Pugmire points out, "[j] ust as a belief can endure as a dogma, an emotion can persist as a kind of psychological reflex, by dint of habit" (Pugmire 1994, 37). Similarly with intensity: it is not a sufficient condition for emotional depth for "[a]n access of intense feeling, such as a tantrum, the frights, or giddy elation, may just be an excess of it" (Pugmire 2005, 34). This is because the phenomenology of depth is not tied to a particular and specific experience since "experiences that have a particularly high or low phenomenal depth are not just more or less intense but qualitatively different" (Gaebler et al. 2013, 271-272), and consequently emotional depth is also qualitatively different from the experience of emotional intensity.

Acknowledging that deep emotions are more enduring than superficial ones, and that they are more meaningful, more valuable, more important and more essential are not sufficient criteria for identifying emotional depth. And it is possible to imagine a superficial person having a very deep emotional tie to their superficial experiences, as when some people express great emotional intensity when they worry about the next episode of this or that series on television, or about make-up, or about a brand of clothes. Pugmire may reply that the person who feels such emotions is not holding the appropriate harmony between the personal given significance, and the actual magnitude of the importance of these issues. However, it will be hard to show these persons' lack of magnitude when they experience it in such a way that it acquires such magnitude. Not being able to clearly explain to 
others why and when emotional depth is misplaced means emotional depth's intricate nature is not fully grasped to be communicated, making it difficult to show why and when people should revise their emotional shallowness and foster deeper emotions.

Invoking Nagel's essay on "What is it like to be a bat?" (1974) Danto insightfully points out this limitation about naming depth based on its phenomenology. He explains that though we cannot know, as bats know, what is it like to be a bat, it is also the case that, "bats, if they have depths, are no better situated than we for knowing what it deeply is to be a bat" (Danto 1981, 694). This means that when we are in the face of the deep we may not clearly see it as deep for "[i]n the depths there is nothing that counts as being there" (Danto 1981, 695). Perhaps we cannot completely grasp emotional depth's full conditions because experience of an emotion does not come with a clear and distinct label of its depth, and consequently, even Pugmire's more rigorous description of emotional depth cannot acquire sufficient precision.

Nevertheless, experience also grants some recognition of the difference and, at least in education, people guide children's emotional development (Kristjánsson 2002, 18; 2013, 192), often by pointing out to children that some things are not worth crying about in comparison with others. The parent who pays less attention to a fit of anger about something superficial and gives attention and care upon anger about a felt injustice is guiding the child to distinguishing the superficial from the deep. Writing about emotional education and emotional development, De Sousa suggests that emotional learning is similar to aesthetic education (De Sousa 1990, 436). Building upon this suggestion it is possible to propose that just as aesthetic sensibility can be fostered by experiencing art in a variety of settings and formats, which offers ways to compare and contrast aesthetic qualities, emotional education requires incorporating the identification of deep emotions in contrast with what is superficial by placing emotions into perspective and thus adding meaning to their distinction. This means that talking and reflecting with others about how emotions arise in stories aids grasping and understanding them (Lipman 1995, 5; Kristjánsson 2001, 10). 
Danto describes a similar insight about how contrast between surface interpretation and deep interpretation provides an added perspective upon action. He shows how when we adopt the theoretical posture of taking up a practice of archeology about actions, we get a more complex picture of action in which two levels of interpretation are given. As Danto explains, we have a picture in which a certain action is done and described in a certain way (a), and when we adopt a certain new theoretical posture a new different description of it appears (b). The meaning of the action is only brought about when we understand that in doing action (a), action (b) is what really is being done, such that "it is hidden from the a-doer that he is a b-doer. A deep interpretation of a identifies it as b, whereas a surface interpretation identifies it as a" (Danto 1981, 698). This means that the deep interpretation gives another meaning to the superficial one and yet one cannot see it without having the superficial one as well because one cannot insightfully claim that the a-doer is really a b-doer without the two interpretations. If we transfer Danto's explanation about interpretation to emotions, we can say that once we have access to deep emotions that underlie an experience, the superficial ones change their meaning and become less crucial and important by comparison, even if they persist in intensity and continue to appear in experience. However, without the superficial emotional experience there is no way to grasp what are the deep ones and how they are revealing, and it is impossible to understand their meaning and the renewed meaning of the superficial ones.

To clarify this point let me illustrate it with a metaphor about the water at the bottom of a well. Imagine someone looks into a well from the top. The person may not be able to see what there is at the bottom. The person can perhaps verify the existence of water by throwing a stone in the well and finding out through the sound of the splash if it is worth the effort of lowering a bucket. Once the bucket has been lowered and water from the bottom raised to the top, the water will look no different from the water one obtains from the surface of a lake, and at most the person will recognize that there are two possible levels at which one can find water, and that the bottom of the well requires a more complex process to be reached, in which a person can learn more about their abilities and about the dimension of the world. Discovering our deep emotions is similar: the process of identifying 
emotional depth can reveal aspects of the world and abilities to interact with it. It is recommended because it enables the ability to distinguish which emotions to take seriously and which ones to treat with lightness by putting emotions in perspective by establishing a contrast.

One of the ways in which people learn to build emotional perspective - of placing deep emotions in contrast with superficial ones — is by listening and being asked to describe things in narratives because when people describe a situation someone else or themselves are living, they construct a narrative that places emotions in perspective. For example, a story about how a person can laugh at a silly joke among friends while still feeling intense sadness and the beginning of grief for the cousin who died in a motorcycle accident will identify that the laugh is not a deep sense of joy but instead a way to show the appreciation for friendship in a deep, difficult confrontation with the loss of a family member and with death. That is, stories put emotions into perspective by indicating that not all emotions are visible all the time, and that some emotions are at the surface while others are hidden for a variety of reasons. This enables understanding how some emotions are more crucial than others, and that some are more decisive and deeper than others in what concerns the self. In addition, depth comes with the recognition that there are different levels of depth and superficiality and emotional depth is a matter of degree of depth and not a quality that an emotion either has or lacks. Consequently, stories also reveal different dimensions of depth and how these are related to each other.

\section{Narrative Structure of Emotion}

The ability of developing stories to put emotions into perspective is recognized by different philosophers who work on Emotion Theory when they claim that emotions have a narrative structure. Here are some examples: Martha Nussbaum writes, “[e]motions, we now can see, have a narrative structure," (Nussbaum 2001, 236) pointing out how the cognitive emphases in philosophy of emotions has shown the crucial importance of emotions' narrative structure. Nussbaum thinks that without this narrative history we cannot have a complete understanding of emotions because, she writes, "[ $\mathrm{t}]$ he understanding of any single emotion is incomplete unless its narrative history is grasped and studied for the light Rev. Filos., Aurora, Curitiba, v. 31, n. 54, p. 671-694, set./dez. 2019 
it sheds on the present response" (Nussbaum 2001, 236). And she reinforces the importance of the narrative stating that certain things about emotions can only be grasped by it. She writes "[ $\mathrm{t}]$ his is what Proust meant when he claimed that certain truths about the human emotions can be best conveyed, in verbal and textual form only by a narrative work of art" (Nussbaum 2001, 236). In Upheavals of Thought: The Intelligence of Emotions (2001), Nussbaum suggests that the narrative mirrors the structure of an emotion and that only an artistic version of the sequence of the relevant events, actions, thoughts, and feelings can truly grasp emotion's structure arguing that the narrative structure of emotion is complex and refined.

Annette Baier also refers to the history underlying an emotion when she states that, "the full content of an emotion always refers to the past, whatever else it refers to. Emotions are history-laden states of mind" (Baier 1990, 18). She adds another criteria to emotions' narrative structure when she further explains that "[c]hildhood, adolescence, youth, maturity, old age, will be relevant to the appropriateness of given emotions, in a way it is not to either the truth or the reasonability of holding particular beliefs" (Baier 1990, 19). That is, Baier thinks that narrative structure of an emotion must also take into consideration the temporal path of the person who feels the emotion and somehow provide the temporal perspective of the person who experiences the emotion.

De Sousa also points out emotions' narrative structure when, in The Rationality of Emotions (1987) he argues that, "we acquire the capacity to talk about emotions in terms of the stories that give rise to them" (De Sousa 1987, 183). De Sousa thinks that while learning these stories we are learning paradigm scenarios that are then associated with our vocabulary of emotions. The backbone of the notion of paradigm scenario is the story that is somehow present in paradigm scenarios such that "by the time toddlers are four to five years old, they have a very good sense of what kinds of stories lead to what simple emotions" (De Sousa 1987, 183). The use of the term "narrative" in De Sousa's work is closer to a simple notion of a sequence of events just as presented in a children's story and it does not require the artistic, creative touch that Nussbaum seems to demand. However, the notion of paradigm scenarios aims to be a technical term and consequently these paradigm scenarios do not need to be interpreted but are used to interpret situations that 
happen in life and can be turned into narratives (De Sousa 1990, 438). It is important to note that De Sousa stresses the open-ended character to emotions' narrative structure pointing out that "a paradigm can always be challenged in the light of a wider range of considerations than are available when the case if viewed in isolation" (De Sousa 1987, 187), giving stories and experience the capacity to increase complexity of already existing paradigm scenarios.

Although the previous examples are a good sample of many different thinkers who consider emotion to have a narrative structure, it is also clear that they use the notion of narrative in different ways. It is beyond the scope of this paper to verify if these different ways are contradictory or if, on the contrary, they can all be accommodated. Nevertheless, it is common to all authors that the notion of a narrative structure of an emotion means that there is a sequence (events, actions, thoughts, feelings), and that the sequence takes the format of a story that provides a temporal organization that gives insight about the nature of an emotion.

The narrative structure of emotions is also a way to better understand emotions' connection to the self. The insightful power of narrative for self-identity is testified by how narratives are one of the best ways to understand us and other people, and to make sense of our own actions and of others (Gallagher 2006, 228). Peter Goldie, who also speaks of the narrative structure of emotion, explains precisely how this narrative structure of emotion enables an important connection to the narrative of life. He claims that it is the underlying narrative structure of emotion that enables an understanding of the complexity of an emotional state because narrative involves a variety of elements described in an organized whole, in which connections between different parts and different elements among themselves and to the whole are made visible. He further writes that, "[a] particular emotion has a complex narrative structure which unfolds over time" (Goldie 2002, 101), and explains that an emotion has several emotional episodes which include a variety of different elements such as perceptions, thoughts, bodily changes and feelings. That is, emotion has a narrative structure because life has a narrative structure. Goldie writes, “[a] person’s emotion will comprise elements or episodes which are bound together as part of a narrative structure which makes best sense of this aspect of the person's life" (Goldie 1999, 395). 
Pointing out that emotions are best understood in light of a narrative structure does not mean this is the only way to understand them. As Shaun Gallagher points out, the insightful nature of narrative and the recognition that emotions are well suited for being captured by a narrative format "doesn't mean that our understanding of others requires an occurring or explicit narrative story telling: but it does require the ability to see/to frame the other person in a detailed pragmatic or social context, to understand that context in a narrative way." (Gallagher 2006, 226) The importance of how narrative best grasps the dynamic nature of emotion is revealed also by how they provide perspective upon emotions showing more clearly the contrast of the deep from the shallower emotions.

The suggestion that narrative is a tool for seeing depth may inadvertently imply that although depth is not installed by narrative, it is captured by it. However, several problems and objections can be raised. The first objection is that it is easily seen how in the animal kingdom, at least for mammals, some things are more crucial and important than others, and therefore some things will matter emotionally more deeply than others. For example, nonhuman animals grief (Nussbaum 2017, 138) and the testimony as well as the experience of animal researchers "supported by empirical data, show that many animals experience deep emotions ranging from joyful glee when playing to bereavement, grief, and depression over the loss of a mate, child, or other friend" (Bekoff 2002, 103). Yet, animals do not seem to have access to narratives the way humans do, and this means the way narratives captures perspective is an incomplete description of how to understand emotional depth.

A second objection may be raised arguing that it is when words fall short of being able to express the emotional experience that something deep has been felt. This happens precisely because "the feelings evoked are so very deep (perhaps primal) that there are no words rich enough to convey what we feel" (Bekoff 2006, 280). The suggestion that narrative captures emotional depth risks not only being incomplete, but completely off target for it is what is not possible to capture by words or description what signals emotional depth ${ }^{1}$.

\footnotetext{
${ }^{1}$ Many thanks to Danil Razeev, Daria Chirva and Maria Sekatskaya for raising these problems at the presentation of an earlier version of paper at the international Conference "Ontology of
} 
Finally, a last general objection may point out that the notion of narrative itself is a problematic concept with many difficulties and troubles that plague it as a theoretical tool (Currie 1998, 654). One difficulty are the rival definitions of narrative in the literature, and the previous description of how philosophers of emotion differently describe the narrative structure of emotion is a natural consequence of this plurality of definitions. For example, Levingston describes three different definitions of narrative (Levingston 2009, 26): the first definition is the minimal conception of narrative, which entails the presentation of one event minimum or one change of affairs, and can easily be recognized in the previous description of the narrative structure of emotion as the description offered by De Sousa. The second one, which Levingston describes as a slightly more complex notion of narrative which incorporates a series of casually related events, and finally, the third and final notion of narrative, an even more complex notion which entails a discourse from the perspective of an agent in which we can identify goals, obstacles and a sequence of a path to achieve the goal and where the narrative explains the causal structure of the sequence of events (Levingston 2009, 26). Levingston criticizes all three definitions writing that the first is too vague, and easily raises disagreement about what counts as a narrative and what are its minimal criteria. The second definition requires an explanation and justification and a good theory of metaphysics of causation, which is often not offered by these same authors (Levingston 2009, 27). The third definition has been criticized by making the problem-solving description the central trait of narrative (Bruner 1991, 10). In face of these problems, Levingston concludes that, despite its continuous use, narrative remains a deeply ambiguous term (Levingston 2009, 28).

In addition to the problem of definition, there are other difficulties to consider when we take emotion to have a narrative structure. The suggestion of a narrative structure of emotion raises the question of who the narrator of a specific emotion should be. That is, it is not clear whose perspective is taken when telling the narrative: if it is the individual who experiences the emotion, or if it is an external

Subjectivity: Selves, Persons and Organisms" at the Institute for Philosophy of St. Petersburgh State University (September 2015). 
perspective of someone who sees another experiencing the emotion, or if it is some type of god-like position from which the narrative structure of an emotion is described, or if it is an even more abstract notion of narrative in which we consider this narrative as a sort of story that occurred and that no one is telling it (Currie 1998, 655). This issue raises a subsequent difficulty of wondering who the narrative is addressed to and to question who is the "implicit 'narratee' of figure to whom the narrative is addressed" (Levingston 2009, 27). A third difficulty is given with the issues regarding the format of such narratives. It is not clear if it is a common format for all emotions or if different emotions require different narrative schemes. Clearly, narratives are commonly linear and take things one after another. That is, when we consider the narrative structure of emotion we may be promoting a linear temporal description such as, for example, first the subject sees the snake, then feels fear, then the subject runs or, to use James' modified version of sequence, first the subject feels bodily modification in face of an event, then perceives the modifications, then feels fear and then runs (James 1984, 189-190). However, one can argue that in the case of emotions one needs a much more complex format, closer to Nussbaum's description, in which temporal jumps are allowed and cherished for accurate descriptions of different emotions and subtle details of phenomenological experience and interpretation of the experience. In sum, what type of format should be adopted to understand emotions' narrative character is not clear. Even if one would adopt a position in which a multiple of narrative formats would be allowed, an explanation of the selection and variation of narrative format accepted would still be required.

\section{Profundity}

The reply to the above objections and problems lies in understanding that there is a difference between deep and profound. So far, we have acknowledged that deep emotions are important because they grant us a sense of emotional perspective that is absent from the mere horizontal description of emotions, and that this added dimension of thickness of emotions grants perspective upon the world and of ourselves. However, the identified contrast in perspective reveals something else about emotional depth: what is initially hidden is not necessarily equivalent to profound. This is why Danto writes, "[d]epth, needless to say, has 
little to do with profundity" (Danto 1981, 695). One can have deep emotions that are self-revelatory but that one would not necessarily describe as profound.

Cataldi and Pugmire both use deep and profound as synonyms because they take deep emotions as being unquestionably connected to things worthy of being profound. The reflection undergone earlier shows that there is a distinction between the two because one can only recognize an emotion as deep if it is in contrast with what is superficial. When the contrast is established, what is hidden becomes more visible, and it is also possible to see that sometimes what is hidden is not important. Thus, what is deep and hidden is not immediately equivalent to what is profound. However, revealing what is hidden and putting emotions in perspective with the contrast between superficial and deep is crucial to help unmask what is important, central and worthy of being profound. This means that uncovering the deep can be revelatory to the point of transformation. Once deep emotions are revealed, people are in a position to acknowledge what they think is crucial and important. The suggestion of gaining perspective by contrasting superficial and deep shows that the deep is transformative, not because it reveals what is already profound, but because it can be an important step towards attaining profundity.

Take for example an adult who is afraid of water because of a traumatic experience in the early years of their life. Knowing that the fear was acquired at a younger age that one has no memory of may explain the sense of depth of its present, but it would not be taken as a profound insight about water, about fear or about the relationship between persons and water. Now imagine that this person does not know about this traumatic experience and has no recollection of the event. The deep sense of fear of water is present and acts invisibly, appearing as a strange sense of anxiety around water. If the person discovers the occurrence of a traumatic experience with water in their first years of life, the deep emotional reaction may become more visible and its force no longer works in the dark. The person who discovers that their deep fear of water is due to a traumatic experience in their childhood may not be able to annihilate feeling scared near water but the person will know that such intensity is not profound for it is not linked to the very nature of water, the very nature of personhood, nor to a crucial connection between persons and water. 
The deep feeling of fear will be recognized as somewhat accidental even if it does not feel that way, and its felt appearance of importance has to do with the specific genealogy of the feeling, and should consequently be treated with some lightness concerning the evaluation of danger in face of water. Nevertheless, the felt importance also reveals a profound commitment to the importance of life and this may bring a whole different type of focus to the person who suffers from this fear. Discovering the source of the fear by the narrative about one's childhood, and the recognition of how intense the commitment to life is can be transformative. However, narratives of the past are not always available and sometimes the ones that are available do not grasp what is hidden as to allow the distinction between what is deep and what is profound. In fact, the source may not be a clear-cut story as is suggested in the given example, and the source may be much more subtle and complex and not grasped by the identification of a single reason. Nevertheless, it is by exploring the power of narratives that the distinction between deep and profound is made clear, and it also enables identifying what should be dealt lightly and what should be dealt with commitment. How a story about a person and their feelings and emotions is told helps that person and others around that person to capture what is fundamental and distinguishes it from what is superficial.

There are a variety of reasons why narratives have this power to unlock insight. The first reason is that the notion of narrative is very suited for emotions (Gallagher and Hutto 2008) because it is particularly suited to the description of agency (Currie \& Jureidini 2004, 415). The way narratives are selective and perspectival (Lamarque 2004, 398) allows us to integrate the selective and perspectival character of a felt emotion and also make it reasonable how emotional distortion can be evaluated differently for "[a] novelist who deliberately distorts historical events for artistic ends is not subject to the same judgment as the historian whose distortions are due to ignorance, bias or deception" (Lamarque 2004, 399). Similarly, distortion of emotions is sometimes a crucial element to fully understand them.

The second reason is that narrative demands attention to detail, and in emotional experience details matter greatly. A pang of jealousy felt by a spouse can be caused by a small detail in a conversation, as when a husband looks subtly away 
when the name of a person is implicitly present in a description of an event at work. The notion of narrative enables us to capture this sensibility to details that is part of emotional life. For example, jealousy can be triggered by the way the story is being told, and the way details rise to the surface and become crucial. Fiction writers are masters of naming out details and, even more to the point, of disguising their relevance for the reader such that their crucial meaning is later found out in the story — detective stories are the easiest and clearest examples.

The third reason why narratives foster insight about depth is that they seem to be capable of capturing emotional experience in its movement such that there is nothing outside the story for an emotion because a "story begins with the circumstances that initiated some affect, or sequence of affects, and it ends when the emotional sequence is in some way brought to a close" (Velleman 2003, 14). As Jerome Bruner writes, narratives are a way to capture "lived time" (Bruner 2004, 692) and in emotion that is really crucial for it is not just the felt emotion that captures the emotional episode but the antecedent conditions and the subsequent actions, emotions and events that make justice to the full understanding of jealousy or of an instant of fear. This ability of narrative to capture lived time allows us to recognize the relevance of the type of self in the emotional episode, how different contextual conditions have decisive impact on felt emotions, and how other emotions interact in the structure of a specific emotion.

The fourth reason why narrative unlocks insight for emotional experience is that narratives provide a mode to compare, contrast and connect the emotions of others and our own. In this regard Goldie writes,

[i]n understanding through reason and imagination, we use the information which we have about another person to, as it were, piece together or fill in the gaps in the narrative structure by bringing to light the episodes of the emotion in a way which will make best sense of this part of his life; "piecing together" and "filling in" the narrative structure are, in fact, just the appropriate metaphors (Goldie 1999, 397).

Goldie distinguishes several different ways in which people grasp other people's emotions (Goldie 1999, 395). First, one can understand and explain another's emotions by understanding the content of a story (e.g. when someone tells a story of seeing a snake while camping the listener can identify that it is a scary experience). Second, one can be emotionally caught by someone else's emotion, as when someone begins to feel scared by seeing someone in a campsite running in a 
scared way to the river and thus becomes alert to possible signals that trigger fear in that context. Third, one can centrally imagine the other's emotional experience from the internal perspective where the person tries to imagine being the other person who is experiencing the emotion. Fourth, one can imaginatively put oneself in another's shoes and try to imagine what one would do if placed in the situation of another and narrating the same event as it happened to another by being oneself as the subject of the emotional experience. The difference with previous description is that here one brings a deliberate mixture of one's own character into the process. Finally, one can focus on the outcome of the event and recognize the other person's difficulties, and while experiencing feelings of distress for the other person become motivated to alleviate those difficulties in some way.

All of these ways to grasp someone else's emotions show that without the tool of narrative it would be much harder to explore different modes of thinking about other people's emotions. Ultimately when we recognize how narrative provides a tool for such differentiation we better understand how narratives have a powerful effect on the imagination and, in doing so, can also affect motivation (Currie \& Jureidini 2004, 419) and the way we think about our own emotions and recognize that a narrative provides not the "familiar patterns of how things happen, but rather [the] familiar patterns of how things feel' (Velleman 2003, 19).

Finally, the last reason that makes narrative insightful is that it is a way to handle emotional complexity and emotion research needs to "take complexity seriously rather than ironically and acknowledge it by default" (Colombetti 2005, 123). Emotional complexity is given by narrative because it captures emotion's dynamic nature, and the interaction of the person who feels it with the world. Perhaps more importantly, the story-telling cannot be substituted by a sequence of reasons-giving that come out of the narrative. The details, tones and nuances offered by the stories go beyond the list of reasons they offer ${ }^{2}$. This is also why they

\footnotetext{
2 Many thanks to Prof. Douglas Cairns and his question on the presentation of the paper at the "The Art of Feeling. Emotions Across Disciplines and Genres" in Lisbon (June 2019), and subsequent lively discussion for refinement of the argument.
} 
cannot be tailored to the persons' needs even though they are an intrinsic part of who they are. As Wollheim writes about it,

This interaction is embedded in the narratives that we associate to our emotions, and in these narratives, conscious or unconscious, lie the identities. But we must not think that these narratives are stories that we can make up at whim or at will. They are probably as deep as anything that we know about ourselves (Wollheim 1999, 224).

In sum, to benefit from gaining perspective upon emotions we cannot simply invent narratives. When stories are not available, or when the ones available do not enable a way to distinguish the deep from the profound, it is necessary to enter the process of storytelling - to explore the various dimensions of narrative that can provide new possibilities and investigate different takes - to see what is profound. Though none of the philosophers of emotions who identify the narrative structure of emotion consider it, we may easily imagine that there can be two different versions of the same narrative just like we have "two photographs of the same scene from different angles" (Currie 1998, 656). This means that the same narrative structure of emotions can be differently described with variation in styles, perspectives and focuses of attention.

The process can be long, and it also has no guarantee that exploring storytelling will for sure end up making people able to separate the wheat from the shaft. However, if the story-telling research is complete and succeeds in uncovering the deep emotions, such that it harvests insight to distinguish it from profound, it can offer a transformative experience. This transformational move is perhaps the reason why deep is taken to be revelatory and self-revelatory and provides a way to get novel perspectives on experience and life. Cataldi writes, "after a 'deep emotional experience' we may say that we are 'not the same person' or we may realize that we are beginning to see things in a different way or in a different light" (Cataldi 1993, 1).

It is the problems and difficulties of narrative that also hold its richness and can be used to distinguish the deep from the superficial. And it is this added step that distinguishes the effect of emotional depth in animals. Animals may have sufficient emotional complexity to have superficial in contrast with deeper emotions, but without the use of language that narratives require, they do not appear to have the voluntary transformative experience of uncovering deep 
emotions to identify and commit to the profound ones. Animals do not need to reach the peaceful sense of the profound because they do not appear to have to choose among values or establish a hierarchy of values. Life is the ultimate value. For humans the notion of a good life requires that values be discussed, compared and chosen. More importantly, humans do not do this process in isolation, and the search for what is a "good life" is a social and cultural ongoing conversation in which narratives play a decisive role in sharing, communicating and interpreting experience.

People reach the stage of sharing deep emotions without speaking not because deep emotions do not require words but because they have reached the sense of deep emotions and are able to share it without having to tell a story. That is, as a species we count on other people's ability for storytelling to discern the deep from superficial emotions. The profound needs an added step and can perhaps more easily be identified in a narrative format when someone has to retell a story such that the contrast between the deep and the superficial mirrors a choice of values.

The reflection of emotional depth opens a totally new field of research for emotion theory. Researches can be sure of its reality for it is because there is superficial versus deep emotions that emotional depth is revealed as such. And although uncovering the deep is difficult and requires work and progress to show what is hidden, the outcome of the distinction of deep from what is superficial increases meaning even though the process can be hard, slow and challenging. Once the deep is uncovered it is possible to separate it from the profound and then open the possibility for transformative experiences. When the deep is identical to profound no transformation necessarily happens for the only thing that occurs is the addition of information and insight about knowing oneself and the world a little better, confirming what was already present. This means that even though diving deep into our emotions can be a way to better understand ourselves and answer the ongoing questions about our self-identity, the decisive moment of uncovering the deep is located in its distinction from the profound, and the commitment to action guided by such transformation. When profound emotions are recognized people are at peace, and while the process of uncovering the deep is turbulent and always 
in relation with what is at the surface, the profound is a commitment that can guide action in a calm and steady fashion. This meaning of emotional depth and its contrast with the superficial is only fully understood when a sense of the profound is uncovered and established by narrative. Ultimately this means that the ability to reach the profound is not a given, and it further reinforces the importance of acquiring and cultivating narrative literacy (Hutto 2007, 47; Gallagher and Hutto 2008, 28-35).

The ability of transformation in the identification of emotional depth and the distinction from what stands as emotionally profound has been so far absent from research on emotion and may provide a further insight into the ways in which emotions are part of rationality (Williams 1981, 29) such that we can more fully understand when emotional experience tells us something decisive about the world from when they distort our view of things (Goldie 2004, 249).

\section{Acknowledgments}

This research work is supported by national funds through FCT - Fundação para a Ciência e a Tecnologia, I.P., in the context of the celebration of the program contract foreseen in the numbers 4, 5 and 6 of article $23^{\circ}$ of D.L. no. 57/2016 of 29 August, as amended by Law no. 57/2017 of 19 July. This research output falls within the Research Project (PTDC/FER-FIL/29906/2017) also funded through FCT. Many thanks for the insightful informal group discussion at EPSSE Workshop "The Meaning of Moods" at Landgut Castelen in Basel (Dec. 2015) with Achim Stephan; Valentina Petrolinic; Ruth Rebecca Tietjen; Eva Weber-Guskar; Daniel O’Shiel. I am grateful to Danil Razeev, Daria Chirva and Maria Sekatskaya for raising problems at the presentation to an earlier version of paper at the international Conference "Ontology of Subjectivity: Selves, Persons and Organisms" at the Institute for Philosophy of St. Petersburgh State University, on September 2015. Also, thanks to the audiences of earlier presentations of the paper at the $3^{\text {rd }}$ Annual Conference of the European Philosophical Society for the Study of Emotions in Athens (June 2016), and at the "The Art of Feeling. Emotions Across Disciplines and Genres" in Lisbon (June 2019). 


\section{References}

Baier, A. "What Emotions Are About" Philosophical Perspectives, 4 (1990): 1-29.

Bekoff, M. Animal passions and beastly virtues: Reflections on redecorating nature. Philadelphia: Temple University Press, 2006.

Bekoff, M. Minding Animals: Awareness, Emotions, and Heart. New York: Oxford University Press, 2002.

Ben-Ze'ev, A. The subtlety of emotions. MIT Press: Cambridge, Ma., 2000.

Bruner, J. "Life as Narrative" Social Research 71 (2004): 691-711. Originally published Social Research 54 (1987): 1-17.

Bruner, J. “The Narrative Construction of Reality” Critical Inquiry 18 (1991): 1-21.

Cataldi, S. L. Emotion, Depth, and Flesh: A Study of Sensitive Space Reflections on Merleau-Ponty's Philosophy of Embodiment. Albany: State University Press, 1993.

Colombetti, G. “Appraising Valence” Journal of Consciousness Studies, 12 (2005): 103-126.

Currie, G. "Narrative." In Edward Craig (ed.) Routledge Encyclopedia of Philosophy, vol.6, London \& NewYork: Routledge, 1998. 654-657.

Currie, G. and J. Jureidini. "Narrative and Coherence" Mind \& Language, vol. 19 (2004): 409-427.

Danto, A. C. "Deep Interpretation" The Journal of Philosophy, Seventy-Eighth Annual Meeting of the American Philosophical Association Eastern Division, 78 (1981): 691-706.

De Sousa, R. The Rationality of Emotion, Cambridge, Mass.: MIT Press, 1987.

De Sousa, R. "Emotions, Education and Time” Metaphilosophy, 21 (1990): 434-446.

De Sousa, R. “Truth, Authenticity, and Rationality” Dialectica, 61 (2007): 323-345.

Dewey, J. "Psychology" in Jo Ann Boydston (ed.) The Early Works, 18882-1898, Volume 2: 1887. Carbondale and Edwardsville: Southern Illinois University Press, 1967, 3-366.

Gaebler, M.; Lamke, J-P.; Daniels, J.K. and Walter. H. "Phenomenal Depth. A Common Phenomenological Dimension in Depression and Depersonalization" Journal of Consciousness Studies, 20, No. 7-8, (2013): 269-91.

Gallagher, S. The narrative alternative to theory of mind. In R. Menary (ed.), Radical Enactivism: Intentionality, Phenomenology, and Narrative. Amsterdam: John Benjamins, (2006): 223-229.

Gallagher, S. and D. Hutto. "Understanding others through primary interaction and narrative practice" The Shared Mind: Perspectives on Intersubjectivity Eds. In J. Zlatev, T. P. Racine, C. Sinha \& E. Itkonen Amsterdam: John Benjamins. 2008, 17-38.

Goldie, P. “How We Think of Other's Emotions” Mind \& Language, 14 (1999): 394-423. 
Goldie, P. "Emotion, Reason and Virtue" in D. Evans / P. Cruse (eds.) Emotion, Evolution, and Rationality, Oxford: Oxford University Press, 2004, 249-67.

Goldie, P. "Emotion, Personality and Simulation" Understanding Emotions. Mind and Morals, ed. by Peter Goldie, Aldershot/Burlington USA/ Singapore/Sidney: Ashgate, 2002, 97110.

Haybron, D. M. "How do We Know How Happy We Are? On Some Limits of Affective Instrospection and Recall” Noûs 41 (2007): 394-428.

Hutto, D. "The narrative practice hypothesis" Narrative and Understanding Persons, ed. D. Hutto, Royal Institute of Philosophy Supplement. Cambridge: Cambridge University Press, 2007, 43-68.

James, W. “What is an emotion?” Mind 19 (1884): 188-204.

Kristjánsson, K. “The Didactics of Emotion Education” Analytic Teaching, 21 (2001): 5-15.

Kristjánsson, K. Justiffing Emotions: Pride and Jealousy. London: Routledge, 2002.

Kristjánsson, K. Virtues and Vices in Positive Psychology: A Philosophical Critique. Cambridge: Cambridge University Press, 2013.

Lamarque, P. “On Not Expecting Too Much from Narrative” Mind ※ Language, 19 (2004): 393-408.

Lipman, M. “Using Philosophy to Educate Emotions” Analytic Teaching, 15, (1995): 3-10.

Levingston, P. "Narrative and Knowledge" Journal of Aesthetics and Art Criticism 67 (2009): 25-36.

Nagel, T. “What Is It Like to Be a Bat?” Philosophical Review 83 (1974): 435-50.

Nussbaum, M. Upheavals of Thought: The Intelligence of Emotions. Cambridge: Cambridge University Press, 2001.

Nussbaum, M. Political Emotions. Why Love Matters for Justice. Cambridge, Massachusetts/London, England: The Belknap Press of Harvard University Press, 2017.

Pugmire, D. Sound Sentiments. Integrity in the emotions. Oxford: Oxford University Press, 2005.

Pugmire, D. "Real Emotion" Philosophy and Phenomenological Research, Vol. LIV, No. 1 (1994): 105-122.

Scheler, M. Formalism in Ethics and Non-Formal Ethics of Values (trans. M. S. Frings and R. L. Funk). Evanston III: Northwestern University Press, 1973.

Velleman, J.D. "Narrative Explanation” The Philosophical Review, Vol. 112, No. 1 (January 2003): $1-25$. 
Wollheim, R. On the Emotions New Have and London: Yale University Press, 1999.

Williams, B. "Moral Luck," Moral Luck. Cambridge: Cambridge University Press, 1981, $20-40$.

RECEBIDO: 23/08/2019

RECEIVED: $23 / 03 / 2003$

APROVADO: $25 / 05 / 2005$

APPROVED: $25 / 05 / 2005$ 